\title{
Salted roads lead to edema and reduced locomotor function in wood frogs
}

Running title: Road salt and edema in frogs

Keywords: amphibian; bloating; freshwater salinization; pollution; road salt; runoff

Manuscript type: Primary research

The manuscript contains two multi-panel figures and one supplemental table.

Lauren E. Frymus ${ }^{1}$

Debora Goedert $2,3+$

Francisco Javier Zamora-Camacho ${ }^{2,4}$

Peter C. Smith ${ }^{5}$

Caroline J. Zeiss ${ }^{5}$

Mar Comas ${ }^{6}$

Timothy A. Abbott ${ }^{1}$

Silvia P. Basu ${ }^{1}$

Jason C. DeAndressi ${ }^{1}$

Mia E. Forgione ${ }^{1}$

Michael J. Maloney ${ }^{1}$

Joseph L. Priester ${ }^{1}$

Faruk Senturk ${ }^{1}$

Richard V. Szeligowski ${ }^{1}$

Alina S. Tucker ${ }^{1}$

Mason Zhang ${ }^{7}$

Ryan Calsbeek ${ }^{2}$

Steven P. Brady ${ }^{1, *}$

${ }^{1}$ Biology Department, Southern Connecticut State University. New Haven, CT 06501.

${ }^{2}$ Department of Biological Sciences, Dartmouth College, Hanover, NH 03755

${ }^{3}$ Ministry of Education of Brazil, CAPES Foundation, Brasilia, DF 95616, Brazil

${ }^{4}$ Department of Biodiversity, Ecology and Evolution. Complutense University of Madrid. C/José Antonio Novais 12, 28040, Madrid, Spain.

${ }^{5}$ Department of Comparative Medicine, Yale School of Medicine

${ }^{6}$ Department of Zoology, Sciences Faculty, University of Granada, 18071, Granada, Spain

${ }^{7}$ Amity Regional High School, Woodbridge, CT 06525

* Submitting author ORCID: 0000-0001-6119-1363

\footnotetext{
+ Present address: Centre for Biodiversity Dynamics, Department of Biology, Norwegian University of Science and Technology, NO-7491 Trondheim, Norway.
} 


\section{Abstract}

2 Human activities have caused massive losses of natural populations across the globe. Like many groups,

3 amphibians have experienced substantial declines worldwide, driven by environmental changes such as

4 habitat conversion, pollution, and disease emergence. Each of these drivers is often found in close

5 association with the presence of roads. Here we report a novel consequence of roads affecting an

6 amphibian native to much of North America, the wood frog (Rana sylvatica). Across 38 populations

7 distributed from southern to central New England, we found that adult wood frogs living adjacent to roads

8 had higher incidence and severity of edema (bloating caused by fluid accumulation) during the breeding

9 season than frogs living away from the influence of roads. This effect was best explained by increased

10 conductivity of breeding ponds, caused by runoff pollution from road salt used for de-icing. Edema

11 severity was negatively correlated with locomotor performance in more northerly populations.

12 Interestingly, northern populations experience more intense winters, which tends to result in more de-

13 icing salt runoff and increased energetic demands associated with overwintering cryoprotection needs.

14 Thus, this emerging consequence of roads appears to impose potential fitness costs associated with

15 locomotion, and these effects might be most impactful on populations living in regions where de-icing is

16 most intense.

\section{Introduction}

19 Human activities are a leading driver of wild population declines, extirpations, and extinctions, culminating

20 in the loss of global biodiversity (Ceballos et al. 2015, Leigh et al. 2019, Rosenberg et al. 2019). These

21 losses shorten the branches of the tree of life and leave lasting if not permanent alterations to long-

22 evolved interactions among species (Emer et al. 2019), modifying ecosystem function and the services

23 they provide (Symstad et al. 1998, Cardinale et al. 2012).

Among the many groups of organisms declining across the globe, amphibians have captured a

25 special place in the attention of researchers, fueling a surge in scientific inquiry over the past three

26 decades (Green et al. 2020). Causes of declines in amphibian populations are complex and dependent

27 on both regional context and species-specific adaptations, but unsurprisingly share a common theme of

28 human activity (Grant et al. 2020). Drivers include habitat loss and alteration, pollution, climate change, 
and disease. These and many other human-mediated drivers can act synergistically, confronting populations with conditions far exceeding the capacity of existing trait variation or the potential for adaptive evolutionary or plastic responses (reviewed in Green et al. 2020). thread: roads. The planet is swathed in some 64 million km of roads (Central Intelligence Agency 2013), with 25 million km more expected by 2050 (Dulac 2013). This vast network contributes an extensive and generally negative set of impacts on natural populations (Trombulak and Frissell 2000, Fahrig and Rytwinski 2009), even as some may be adapting (Brady and Richardson 2017). Perhaps most direct and apparent, roads result in huge numbers of road kill - dispatching up to 1 million vertebrates per day in the U.S. alone (Lalo 1987) - a phenomenon that disproportionately affects amphibians (Glista et al. 2008). Roads can facilitate the spread of both disease (Urban 2006) and invasive species (Mortensen et al. 2009); they fragment habitats (Reed et al. 1996), reduce connectivity (Shepard et al. 2008), and affect

41 dispersal and gene flow (Riley et al. 2006). Roads are also substantial sources of pollution. Leaching and 42 stormwater runoff have deposited countless contaminants into the environment for decades (Huber et al. 2016). Many contaminants can reach toxic levels in soil, surface waters, and groundwater (Marsalek et al. 1999, Tang et al. 2013, Mclntyre et al. 2018), and these effects can extend to habitats located well beyond the road (Forman and Deblinger 2000). Some contaminants are fleeting, broken down by chemical or biological processes, but others are long-lived or inert and tend to increase over time

47 (Kaushal et al. 2005). In short, this singular and physically narrow change to the landscape caused by roads spurs numerous and wide-reaching drivers of population decline. Identifying and understanding these drivers and their effects is essential for conservation efforts.

In areas with cold winters, a chief pollutant threatening amphibian populations is road salt. Due to

52 common and widespread (Mullaney et al. 2009, Corsi et al. 2010). Even in large waterbodies (e.g.,

53 permanent ponds, lakes), runoff pollution can result in substantial salt concentrations exceeding national

54 water quality criteria for aquatic life (Dugan et al. 2017, Kaushal et al. 2018). In smaller waterbodies

55 however (e.g., vernal pools, wetlands), levels can be many times higher, approaching brackish conditions

56 typical of coastal waters, a stark contrast to the generally salt-free conditions of small, inland surface 
57 waters. For many pool-breeding amphibians, these smaller waters are critical sites for reproduction, where embryos and larvae develop before metamorphosing and dispersing into terrestrial habitats.

59 Across the complex life-history cycle common to many amphibians, sensitivity to salt tends to be highest 60 for embryos and larvae (Gordon and Tucker 1965, Uchiyama et al. 1990, Karraker et al. 2008, Albecker and McCoy 2017). Thus, pool-breeding amphibians tend to face salt pollution at peak sensitivity, and this

62 timing often coincides with annual peaks in salt concentration that occur after winter. At high enough

63 concentrations, salt causes outright mortality in amphibians (Sanzo and Hecnar 2006, Brady et al. 2017).

64 At lower concentrations, sublethal effects are numerous. Aquatic-stage exposure to salt affects behavior

65 (Denoël et al. 2010) and modifies growth and developmental rates (Dananay et al. 2015, Brady 2017), it 66 increases malformations and susceptibility to disease (Karraker and Ruthig 2009, Brady 2013, Hall et al.

67 2020), and it causes 'carry-over' effects, negatively impacting post-metamorphic survival in the terrestrial

68 environment (Dananay et al. 2015); all of which can contribute to observed population declines (e.g.,

69 Karraker et al. 2008).

In the present study, we investigated an additional and novel physiological consequence of roads:

71 severe gross edema found in adult frogs breeding in polluted, roadside ponds. Although edema is

72 recognized as a disorder in veterinary and disease literature (e.g., Hadfield and Whitaker 2005, Miller et

73 al. 2011), its occurrence and causes in natural amphibian populations have been overlooked (but see Hall et al. 2017). For the wood frog (Rana sylvatica) - the focus of our study - temporary edema can be found

75 among breeding adults in early spring, apparently resulting naturally from overwintering physiology.

76 During spring thaw, the reversal of the process whereby water is sequestered out of cells to prevent intra-

77 cellular ice formation, is thought to cause temporary edema (Kling et al. 1994, Irwin et al. 1999). However,

78 our preliminary observations suggest that spring edema is more severe in populations from polluted,

79 roadside ponds compared to those from unpolluted, woodland ponds.

Here, we quantified the severity of edema in wood frogs from 38 ponds in New England, where

81 road salt pollution is common. We posited that road salt might be causing severe edema, and therefore

82 asked whether variation in edema prevalence and severity correlates with road adjacency and water

83 conductivity, and if edema prevalence and severity increases with age, a proxy for lifetime exposure. We

84 also investigated directly the effect of roadside pond water on edema by estimating body mass gain for 
85 animals exposed to water from roadside versus woodland ponds and compared to spring water. Next, we used dissections and histological preparations to characterize the relation between edematous outward

87 appearance and potential underlying signs and causes. Since edema could be associated with winter

88 physiology and spring thaw, we also asked if blood glucose levels correlated with edema severity. Finally, we investigated a potential fitness cost of edema. Specifically, we asked how jumping performance, a commonly used fitness proxy for frogs, is affected by edema severity.

92 Methods

$93 \quad$ Natural history

94 Wood frogs are widespread in North America, ranging in distribution from the eastern southern

95 Appalachian Mountains and extending north- and westward to the Alaska-Yukon region within the Arctic 96 circle (Martof and Humphries 1959, Green et al. 2014). To survive winter conditions, particularly in higher 97 latitudes, wood frogs rely on physiological adaptations to freezing (Storey and Storey 1988, Costanzo et 98 al. 2015). Wood frogs typically use ephemeral or other small, fishless ponds for breeding in early spring.

99 Across our study area, breeding occurs typically between early March and mid-April, lasting about 1-2

100 weeks in any given pond. Immediately prior to breeding, adults migrate from upland terrestrial habitat to

101 mate in ephemeral ponds. Males amplex females and fertilize eggs externally during oviposition. Each

102 female lays a single clutch as an egg mass containing approximately $800-1100$ eggs. Embryos develop

103 over 2-3 weeks before hatching and continue to develop as aquatic larvae throughout spring and early

104 summer until they metamorphose into terrestrial juveniles, which disperse into upland habitat. Adults can

105 live for 5-6 years (Berven 2009, Brady et al. 2019), and apart from annual breeding, tend to spend most

106 of their lives in terrestrial habitat. Juvenile wood frogs show strong natal site fidelity and, as adults, strong

107 breeding site fidelity (Berven and Grudzien 1990).

108

109 Edema severity/prevalence and environmental variation

110 We quantified edema by compiling data for 935 individual frogs from 38 breeding ponds (putative 111 populations, referred interchangeably as "populations" hereafter) in New England ( $\mathrm{N}=20$ roadside, 18 112 woodland; Fig. 1). Following Brady (2013), ponds were categorized as either 'roadside' (<10-15 m from a 
113 paved road) or 'woodland' (> $150 \mathrm{~m}$ from any road). Frogs were captured during four breeding seasons in

114 three different study areas (spanning from 41.2-43.8 degrees North), each containing a mix of roadside

115 and woodland populations: 1) Southern Connecticut ( $\mathrm{N}=9$ roadside, 9 woodland ponds in 2018), 2)

116 Northeastern Connecticut ( $\mathrm{N}=6$ roadside, 5 woodland ponds in 2010), and 3) the Upper Valley of Vermont

117 and New Hampshire ( $\mathrm{N}=5$ roadside, 4 woodland ponds in 2016 and 2017). In Northeastern Connecticut,

118 frogs were captured on their inbound breeding migration using drift fences with pitfall traps placed

119 adjacent to breeding ponds. Frogs from these populations were therefore not exposed to pond water

120 immediately prior to capture. In the other two study areas, drift fences with pitfalls were supplemented

121 with minnow traps. Thus, frogs from these populations had mixed histories of exposure to pond water

122 immediately before capture. Both types of traps were checked daily for new captures. Captured frogs

123 were returned to the lab and dorsal photographs were taken within two days. Edema severity was scored

124 from these photographs on a 1-3 integer scale, corresponding to 1) non-edematous, 2) moderate edema,

125 and 3) severe edema. For the analysis of prevalence, an individual was considered edematous if it had

126 an edema score of either 2 or 3 . The following environmental variables were measured during the spring

127 breeding / rearing seasons in a subset of ponds: specific conductivity ( $N=31$ ponds), dissolved oxygen

128 ( $\mathrm{N}=29$ ponds), and $\mathrm{pH}(\mathrm{N}=18$ ponds).

129 We used separate mixed models to evaluate the effect of population type (roadside vs. woodland)

130 on 1) edema severity score and 2) edema prevalence. Edema severity was fit using a linear model with a

131 Gaussian distribution while edema prevalence was fit using a binomial model with a logit link. In each

132 case, we first used AIC model selection to compare three candidate models fit with maximum likelihood

133 and the following random effect structures: population, population and region (i.e. Southern Connecticut,

134 Northeastern Connecticut, or Upper Valley of Vermont and New Hampshire), and population nested

135 within region. Using a threshold for delta AIC value of 2, the model with the single random effect of

136 population was preferred for both edema severity and prevalence. Fixed effect inference of severity was

137 made after refitting the selected model with restricted maximum likelihood estimation. Here and

138 elsewhere when linear mixed models were used, p-values were based on degrees of freedom calculated

139 with Satterthwaite's approach implemented in the R package 'ImerTest' (Kuznetsova et al. 2017).

140 Because our edema severity data could potentially be considered ordinal, we also composed a mixed 
141 model using the R package 'ordinal' (Christensen 2019). Inference was similar between these two

142 modeling approaches $(P<0.001$ in each case $)$ and we therefore interpreted results from the linear model.

143 For the binomial responses of prevalence, inference was made using a likelihood ratio test between the

144 selected model and a reduced model in which the response mean was used as the sole fixed effect in

145 place of population type (i.e. intercept-only model). In a separate suite of standard linear models, we

146 analyzed edema in response to conductivity, dissolved oxygen, and $\mathrm{pH}$. Pond-level averages of edema

147 score were used as the response variable in each model. Conductivity was log-transformed because of

148 its wide range $(26-984 \mu \mathrm{S} / \mathrm{cm})$ and bimodal distribution between woodland and roadside ponds.

We analyzed the relation between adult age and both edema severity and prevalence using data

from 74 individuals collected in 2014 from 9 populations ( $N=4$ roadside, 5 woodland) in the Upper Valley

of Vermont and New Hampshire. Individuals used in this analysis were collected during the inbound

152 breeding migration (prior to arriving at ponds) using drift fences with pitfall traps. Edema was estimated

153 from photos as described above and age was estimated using skeletochronology of toe clips (methods

154 described in Brady et al. 2019). We used a linear model with either prevalence or severity as the

155 response variable, and the interaction between age and population type for fixed effects.

Exposure-induced change in mass

158 We examined the effects of pond water exposure on adult wood frog water uptake, a potential cause of

159 edema. We analyzed data from a prior study conducted in the same Northeastern CT populations,

160 designed originally to test the effects of early-embryo exposure to polluted pond water on larval survival

161 (see Brady 2017). Briefly, adult frogs were captured during the breeding season using drift fences with

162 pitfall traps adjacent to breeding ponds. All frogs were captured on their inbound migration and thus were

163 not yet exposed to breeding pond water at the time of capture. At each breeding pond, captured frogs

164 were measured for snout-vent length (SVL) and weighed prior to being paired haphazardly to breed in 5.1

$165 \mathrm{~L}$ plastic aquaria filled with $1 \mathrm{~L}$ of either breeding-pond water or spring water. For roadside populations,

166 this design resulted in approximately half the treatments being roadside water and the other half being

167 spring water. For woodland populations, about half the treatments were woodland pond water and the

168 other half were spring water. Across 11 ponds ( $\mathrm{N}=6$ roadside, 5 woodland), an average of 8.5 (range: 4- 
14) breeding pairs were stocked into each treatment (i.e. breeding-pond water or spring water). Exposure

period was determined by the time required to breed. Following breeding, adults were re-weighed.

We analyzed change in body mass relative to SVL for males prior to and after breeding. Females

172 were excluded from this analysis because change in mass caused by water is confounded with change in

173 mass due to oviposition. Specifically, we calculated a body condition index $(\mathrm{BCl})$ as mass per unit SVL

174 (i.e. mass/SVL), both before and after exposure to pond or spring water that occurred while breeding. We

175 then calculated delta $\mathrm{BCl}$ as the ratio of post-breeding $\mathrm{BCl}$ to pre-breeding $\mathrm{BCl}$. Thus, delta $\mathrm{BCl}$ values >

1761 indicate body mass gain whereas those $<1$ indicate body mass loss. We used separate linear mixed

177 models with population as the random effect to analyze both delta $\mathrm{BCl}$ and exposure duration across the

178 interaction of population type and exposure water type. We used the R package 'emmeans' (Lenth et al.

1792018 ) to estimate marginal means for each of these models and to compute $95 \%$ confidence intervals

180 with respect to a null value of 1 (i.e. no change in body mass). We applied Tukey contrasts to make

181 pairwise comparisons of both delta $\mathrm{BCl}$ and exposure duration across this interaction.

Morphology, histology and blood glucose

184 In spring 2020, we necropsied six frogs from Southern Connecticut populations $(\mathrm{N}=1$ with severe edema,

$185 \mathrm{~N}=5$ non-edematous, all male) to identify the underlying source of edema and to evaluate potential

186 changes in gross morphology associated with edema. Following prosection and gross dissection, soft

187 tissues (including gastrointestinal tract, liver, spleen, kidneys, lung, heart, reproductive tissues and

188 remainder of body) were fixed in 10\% neutral buffered formalin, while long bones, associated muscle,

189 nerve and skin, as well as brain and eyes (in skull), were fixed in Bouin's solution for one week. Tissues

190 were processed using standard paraffin processing sectioned at $5 \mu \mathrm{m}$, and stained with hematoxylin and

191 eosin for light microscopic evaluation. Images were taken with a Zeiss Axioskop and Zeiss Axiocam MrC

192 camera. We also measured blood glucose in subset of 54 male frogs from 6 roadside ponds ( $N=35$

193 frogs) and 4 woodland ponds ( $N=19$ frogs) in Southern Connecticut. We obtained a blood sample using

194 a 30.5 gauge needle to pierce the facial vein (Forzán et al. 2012). A drop of blood was then placed on a

195 testing strip and assayed using a Bayer Contour ${ }^{\circledR}$ Next blood glucose meter. We used a mixed model

196 with population as a random effect to analyze blood sugar in response to edema and population type. We 
197 included body mass as a covariate in this analysis because of its potential effect on blood glucose irrespective of edema related to pollution. The two highest blood glucose observations were removed

199 from analysis because they were 12 and 6.8 times the median absolute deviation.

Jumping performance

202 To evaluate whether jumping performance might be compromised by edema, we conducted jump trials on 203 a subset of frogs scored for edema from Southern Connecticut $(\mathrm{N}=270$ in 2019) and the Upper Valley of

204 Vermont and New Hampshire ( $\mathrm{N}=258$ in 2016 and 2017). Frogs were placed on one end of a $0.91 \times 5 \mathrm{~m}$ 205 piece of brown paper and at least 5 consecutive jumps were recorded, or frogs were placed between two 206 plastic walls (height: $34 \mathrm{~cm}$; length: $3.4 \mathrm{~m}$ ) separated by approximately $30 \mathrm{~cm}$, such that frogs could only

207 jump forward. Frogs were motivated to jump as needed by tapping their urostyle with a finger (Brady et al. 208 2019). Marks were placed where frogs landed and the maximum distance between marks was recorded.

209 We used a mixed model with population as the random effect to analyze the relation between jumping 210 performance and edema. For each frog, we used maximum jump distance from among all jumps in a 211 given trial as the response variable. We analyzed jump performance collectively and separately for the 212 two regions. We also used a mixed model with population as the random effect to analyze whether jump 213 performance varied between the two regions.

\section{Results}

\section{Edema severity/prevalence and environmental variation}

217 Across 38 ponds, edema was more severe and more prevalent in roadside than woodland ponds (Fig. 1).

218 Specifically, model estimates of edema score were 1.84 in roadside ponds compared to 1.46 in woodland 219 ponds $\left(F_{1,30.0}=14.77, P<0.001\right)$. Variance between ponds (regardless of type) estimated from the 220 random effect accounted for $12.3 \%$ of total edema severity variance. The probability of finding edema in 221 roadside ponds was estimated at 0.605 compared to 0.367 in woodland ponds. Edema was therefore $22265 \%$ more prevalent in roadside versus woodland ponds. Among environmental variables, edema 223 severity was correlated with log-transformed conductivity $\left(F_{1,29}=17.72, P<0.001 ;\right.$ Fig 1$)$ but not pH $\left(F_{1,16}\right.$ $224=0.603, P=0.45)$ or dissolved oxygen $\left(F_{1,27}=0.00, P=0.996\right)$. Conductivity averaged $545 \mu S / \mathrm{cm}$ in 
roadside ponds (range: $170-984 \mu \mathrm{S} / \mathrm{cm}$ ), representing a 14-fold increase over the average $38 \mu \mathrm{S} / \mathrm{cm}$

(range: $26-53)$ found in woodland ponds $\left(F_{1,29}=38.57, P<0.001\right)$.

Neither edema severity $\left(X^{2}=0.146, \mathrm{df}=1, P=0.702\right)$ nor prevalence $\left(X^{2}=0.01, \mathrm{df}=1, P=\right.$

228 0.921) varied across the interaction of age and population type. Similarly, when main effects were

229 considered, we found no effect of age or population type on edema severity (age: $F_{1,71}=1.85, P=0.178$;

230 population type: $F_{1,71}=0.207, P=0.651$ ) or prevalence (age: $X^{2}=0.957, \mathrm{df}=1, P=0.328$; population

231 type: $\left.X^{2}=0.003, \mathrm{df}=1, P=0.958\right)$.

\section{Exposure-induced change in mass}

234 Delta $\mathrm{BCl}$, or the change in body mass relative to SVL, varied across the interaction of water type $\mathrm{X}$

235 population type (Fig. 2; $F_{1,339.3}=18.02, P<0.001$ ). Specifically, wood frogs exposed to roadside water

236 had the highest relative change in mass compared to those in all other treatments. Model estimates

237 indicated that roadside wood frogs exposed to roadside water maintained their mass, whereas wood

238 frogs in all other combinations of water and population type lost mass (Supplemental Table 1). The mean

239 duration of exposure was 5.94 days (range of 1-13 days) and differed across the interaction of water type

$240 \mathrm{X}$ population type $\left(F_{1,290.23}=3.97, P=0.047\right)$. Tukey post-hoc pairwise comparisons revealed that the

241 only difference in exposure time was between woodland populations in woodland water versus spring

242 water $(P=0.026$; woodland populations exposure duration: 5.91 days for woodland pond water compared

243 to 4.96 days for spring water; all other pairwise comparisons: $P>0.505)$, indicating differences in

244 exposure time did not drive the effect found in delta $\mathrm{BCl}$ for roadside populations.

\section{Morphology, histology and blood glucose}

247 On gross examination, marked subcutaneous edema was evident in the frog with severe edema (Fig. 2).

248 Upon dissection, edema fluid rapidly dissipated from the subcutis, and was evident to a much lesser

249 degree in the coelomic cavity. In all frogs, the gastrointestinal tract was devoid of ingesta or digesta, no

250 fat stores were present, and testes were well developed. On histology, the grossly edematous animal

251 exhibited subcutaneous edema. Adipose tissue was absent, and bone marrow was characterized by

252 marked serous fat atrophy (or 'gelatinous bone marrow transformation') a condition associated with 
253 starvation and characterized by loss of both fat and red-blood stem ('hematopoietic') cells, and the

254 deposition of extracellular mucous (Fig. 2). In contrast, grossly non-edematous animals had absent or

255 mild subcutaneous edema and greater retention of intact adipocytes within bone marrow. Remaining

256 tissues were unremarkable, with the exception of a trematode segment characterized by an acoelomic

257 body, tegument and intestinal tract within the liver on a non-edematous animal. This was considered an

258 incidental finding. In all animals, spermatogenesis was vigorous.

259 Blood glucose varied with respect to edema severity $\left(F_{1,43.8}=7.00, P=0.011\right)$ and body mass

$260\left(F_{1,27.4}=5.06, P=0.033\right)$ but not population type $\left(F_{1,10.0}=0.05, P=0.831\right)$. When accounting for

261 population type and mass, along with random effects of population, blood glucose increased $13.16 \mathrm{mg} / \mathrm{dL}$

262 with each one-unit increase in edema score and decreased $4.2 \mathrm{mg} / \mathrm{dL}$ for each gram of body mass.

Jumping performance

265 When all populations from the two regions with jumping data were analyzed together, edema was not

266 correlated with maximum jumping distance in (male) frogs $\left(F_{1,183.2}=0.278, P=0.097\right)$. However, separate

267 analyses for each region revealed that edema negatively affected maximum jump distance for frogs in the

268 Upper Valley $\left(F_{1,131}=4.92, P=0.016\right)$ but not for frogs in Southern Connecticut $\left(F_{1,199.4}=0.50, P=\right.$

269 0.479). Specifically, maximum jump distance for Upper Valley frogs declined by $4.3 \mathrm{~cm}$ for each unit

270 increase in edema. Thus, on their best jumps, the frogs with severe edema jumped approximately $9 \mathrm{~cm}$

271 less than non-edematous frogs. Jumping performance also varied between regions independent of

272 edema $\left(F_{1,11.7}=71.05, P<0.001\right)$. Southern Connecticut frogs jumped an estimated $71 \mathrm{~cm}$ compared to

$27349 \mathrm{~cm}$ for Upper Valley frogs. Thus, maximum jump for Upper Valley frogs was about $68 \%$ that of

274 Southern Connecticut frogs.

Discussion

277 Edema was both more prevalent and more severe in roadside populations subject to salt runoff compared

278 to unsalted woodland populations across three different regions in the northeastern USA. In support of

279 salt runoff being a causative agent of edema, we found that edema severity was correlated with

280 conductivity in breeding ponds, and that frogs experimentally exposed to roadside pond water during 
281 breeding increased fluid retention. Edema also correlated with increased blood glucose, as well as with decreased jumping performance in northerly (but not southerly) populations. Together, these results

283 reveal that pollution from roads appears to be increasing the severity of edema in amphibians, and that

284 this relatively unexplored consequence of roads imposes a potential fitness cost through its effect on locomotion.

Our gross morphological and histological findings indicate that fluid accumulation in the subcutis was indeed responsible for the edematous appearance of frogs. Several factors identified from the veterinary literature are known to cause subcutaneous edema, including fungal, bacterial, or viral

289 infection, exposure to low solute water, and kidney diseases (reviewed by Pessier 2009). Interestingly, 290 high salinity water might in some instances help prevent some diseases in amphibians (e.g., Stockwell et al. 2015). However, the consequences of salt runoff for disease susceptibility in amphibians are complex

292 and not fully understood, with some studies suggesting that osmotic stress caused by salt might be 293 detrimental to the survival of individuals in populations with ranavirus infections (Hall et al. 2020).

294 Although we cannot completely rule out ranavirus as a factor, infected individuals typically present 295 ulcerative and hemorrhagic syndromes in multiple tissues (Cunningham et al. 1996, Docherty et al. 2003), 296 which we did not observe in the edematous animal dissected or among the animals scored for edema.

297 In our study, exposure to low solute water can definitively be ruled out as a possible factor, since 298 animals presenting edema were more frequently those exposed to high solute water. Frogs have highly 299 permeable skin and must osmoregulate in aquatic environments. For frogs in freshwater, the tendency is 300 for water to move from the environment into the frog. Curiously, from an osmotic perspective, adding salt 301 to freshwater should decrease the osmotic potential of the external environment relative to that of the 302 frog. That is, by adding ions to the pond, water pressure exerted on frog skin decreases. In contrast, in 303 unpolluted woodland ponds, external water pressure is higher than that found in polluted roadside ponds. 304 Thus, based purely on osmotic pressure, there should be a greater tendency for woodland, not roadside, 305 water to move into frogs. And yet we found edema was more severe in salty, roadside environments, 306 pointing to dysfunction in osmoregulation. Therefore, it is likely that the culprit of edema is kidney 307 disorder, potentially incurred from osmoregulatory stress from prior exposure to high salinity. 
Increased edema severity in roadside ponds might also be linked to overwintering physiology. Beginning in fall as temperatures decline, wood frogs accumulate urea (Costanzo and Lee 2005) and continue to increase liver glycogen stores. During freezing, glycogen is metabolized into glucose

311 (Costanzo and Lee 2013, Costanzo et al. 2015) and distributed to cells and organs. Water is moved to 312 the coelomic cavity and lymph system (Lee et al. 1992), and cytosol moves osmotically to extracellular 313 spaces. These physiological changes help prevent cells from freezing while permitting coelomic and 314 subdural ice formation to occur with little damage to organs and tissue. Estimates indicate that up to 315 about 2/3 of body water can become frozen in wood frogs during the winter (Layne Jr and Lee Jr 1987, 316 Storey and Storey 1988, Costanzo and Lee 2013). Thawing in the spring can be rapid and appears to be 317 a source of fleeting edema (Kling et al. 1994, Irwin et al. 1999) during which time there might be a lag 318 period for water resorption from coelomic and subdural spaces, consistent with our histological and gross dissection findings. Although it is unclear why road proximity might increase severity of thaw-induced 320 edema, conceivably, pollution might trigger a hyper-reactive freeze tolerance response and/or a reduced 321 capacity for resorption. In which case, it is not surprising that we found elevated levels of glucose in the 322 spring, suggesting either that edematous frogs have an amplified cryoprotective response (concentrating 323 more glucose in their cells) and/or they metabolize glucose more slowly after thawing.

324 Regardless of whether edema is linked to winter physiology or a direct consequence of kidney 325 disease, the severity we detected in roadside populations prompts consideration of what conditions in 326 roadside environments increase edema severity. For instance, is edema exacerbated by the aquatic 327 environment, terrestrial environment, or both? For adults in our study, one such exposure could have 328 occurred during embryonic and larval stages (as wood frogs show strong natal site fidelity; Berven and 329 Grudzien 1990) while another exposure could have occurred in adult stages but in prior breeding years 330 (as wood frogs also show strong breeding site fidelity; Berven and Grudzien 1990). In either case, some 331 degree of carry-over effect is implied. Exposure could also occur in terrestrial roadside habitats, for 332 instance through consumption of saltier food items or exposure to saltier soils.

333 The edema we describe occurred in breeding frogs captured either on route to or soon after 334 arriving in their breeding ponds. This means that for at least a subset of frogs, the onset of edema 335 occurred before they were exposed to pond water. This finding indicates that edema sets in either during 
336 the short migration from upland hibernacula to breeding ponds, or that frogs are edematous prior to

337 migration. In late fall, frogs tend to choose overwintering sites close to their breeding ponds (O'Connor

338 and Rittenhouse 2016), such that salt runoff exposure in the terrestrial environment might be

339 exacerbating edema that forms naturally following the reversal of winter cryoprotection. Interestingly, we

340 found no relation between age and edema severity or prevalence, suggesting that a single exposure to

341 the roadside environment might be just as likely to generate edema as a history of adult breeding in

342 roadside ponds.

Our study additionally suggests a significant impact of salt runoff exposure in the aquatic

344 environment. We found higher edema severity with increased conductivity of the aquatic environment, a

345 variable widely used to measure road salt pollution. In New England, like many temperate regions with

346 cold winters, roadside ponds have become salinized due to runoff from road salt (Kaushal et al. 2005,

347 Karraker et al. 2008, Brady 2012, Dugan et al. 2017). Although a variety of salts are used in de-icing

348 practices, $\mathrm{NaCl}$ is the agent applied most abundantly, both in our study region and throughout the U.S.

349 (Mullaney et al. 2009). Conductivity values in roadside ponds averaged $545 \mu \mathrm{S} / \mathrm{cm}$, and individual values

350 ranged up to $2050 \mu \mathrm{S} / \mathrm{cm}$. Based on prior calibrations (G. Benoit unpublished data), we estimate these

351 values correspond to 300 and $1128 \mathrm{mg} / \mathrm{L}$ of total $\mathrm{NaCl}$, or $182 \mathrm{mg} / \mathrm{L}$ and $684 \mathrm{mg} / \mathrm{L}$ of $\mathrm{Cl}-$, respectively.

352 Moreover, we found that frogs experimentally exposed to roadside water during breeding maintained

353 mass on average while those exposed to woodland or spring water lost mass. We interpret this change in

354 mass as being driven primarily by water gain or loss, thus representing a relative increase in water

355 retention or uptake in roadside water, because frogs did not have access to food during this period.

356 Saltier aquatic environments should result in frogs taking up more ions for osmoregulation (Greenwald

357 1972), which could lead to higher water retention (Park and Do 2020) consistent with our findings (Fig. 2).

358 For example, Park and Do (2020) found that exposure of black-spotted frogs (Pelophylax nigromaculatus)

359 to about $9,400 \mu \mathrm{S} / \mathrm{cm}$ resulted in increased blood electrolytes and that frogs became edematous. The

360 authors attribute this effect to renal dysfunction resulting from the increase in electrolytes. Future studies

361 would be required to disentangle the relative importance of pre- and post-metamorphosis exposure, as

362 well as exposure through aquatic versus terrestrial environments. 
Finally, we found that jumping performance was compromised by edema in the more northerly populations of Vermont and New Hampshire, but not those of Southern Connecticut. Here again, overwintering conditions might mediate this effect. For instance, in northern populations, more severe and longer winters should produce more intense cryoprotective physiological changes (Costanzo et al. 2015).

367 This investment in cryoprotection might bear a cost to muscle performance needed for locomotion,

368 consistent with our findings that Upper Valley frogs jumped just $68 \%$ the distance of Southern

369 Connecticut frogs. Costanzo et al. (2015) report that muscle catabolism is an important component of 370 freeze tolerance observed in northern (Alaska) wood frog populations but absent in Ohio populations, and

371 that it results in skeletal muscle atrophy. The authors suggest that this mechanism is essential to increase 372 nitrogen availability for urea production given the more extreme winters in Alaska. Conceivably, harsher

373 winters in Vermont and New Hampshire induce this same mechanism and cause muscle atrophy that

374 diminishes jumping performance. Also, the serous fat atrophy we found with severe edema suggests that 375 edematous frogs consume more energy for cryoprotection. Given the importance of energy and

376 locomotion during spring breeding, particularly in the context of road crossings and swimming

377 performance during mating, these consequences could bear impacts on fitness components including

378 survival and reproductive success and, therefore, on the viability of higher latitude populations.

379 In this study, we investigated possible causes and fitness consequences of increased edema 380 severity, representing an amphibian population threat from roads and runoff pollution that has remained 381 largely unexplored. Increased edema severity in wood frogs appears to be a wide-ranging phenomenon 382 in road-adjacent habitats, driven by road salt pollution. Given the regional distribution of edema reported 383 here, we expect that this phenomenon likely affects wood frogs across much of their range, although the 384 consequences of edema might be most severe for populations experiencing more intense winters.

385 Interestingly, northern areas where winters are more intense tend to use more road salt. Thus, the 386 presence of these multiple, correlated stressors suggests that wood frogs in more northerly populations 387 might be both most likely to experience higher edema severity near roads and locomotor consequences 388 as a result. Many important questions remain about the mechanisms and consequences of severe edema 389 in roadside wood frogs. Indeed, while road salt is a prevalent contaminant and almost certainly the most 390 common pollutant by mass in these ponds, other contaminants could be contributing to edema, such as 
391 heavy metals and aromatic hydrocarbons, and such effects might be interactive. Identifying the causes of

392 severe edema and its impacts on populations should guide future investigations.

393

\section{Acknowledgements}

395 This work was supported by Mianus River Gorge Preserve, Elm City Innovation Collaborative, Yale

396 Institute for Biospheric Studies, EEES Graduate fellowship and Cramer funds, Guarini School of

397 Graduate and Advanced Studies McCulloch Fellowship, CAPES graduate fellowship (SwB 13442/13-9),

398 and the National Science Foundation (DEB \#1011335, DEB \#1655092). We thank D. Skelly for project

399 advice, and J. Peterman and S. Rodrigues for help in the field and lab. We are grateful to the many

400 private land owners and public land managers who allowed us to work on their lands.

401 


\section{Literature Cited}

403 Albecker, M. A., and M. W. McCoy. 2017. Adaptive responses to salinity stress across multiple life stages in anuran amphibians. Frontiers in zoology 14:40-40.

Berven, K. A. 2009. Density dependence in the terrestrial stage of wood frogs: evidence from a 21-year population study. Copeia 2009:328-338.

Brady, S. P. 2012. Road to evolution? Local adaptation to road adjacency in an amphibian (Ambystoma maculatum). Scientific Reports 2.

Brady, S. P. 2013. Microgeographic maladaptive performance and deme depression in response to roads and runoff. PeerJ 1:e163.

411 Brady, S. P. 2017. Environmental exposure does not explain putative maladaptation in road-adjacent populations. Oecologia 184:931-942.

Brady, S. P., and J. L. Richardson. 2017. Road ecology: shifting gears toward evolutionary perspectives. Frontiers in Ecology and the Environment 15:91-98.

Brady, S. P., J. L. Richardson, and B. K. Kunz. 2017. Incorporating evolutionary insights to improve ecotoxicology for freshwater species. Evolutionary Applications 10:829-838.

417 Brady, S. P., F. J. Zamora-Camacho, F. A. Eriksson, D. Goedert, M. Comas, and R. Calsbeek. 2019. Fitter frogs from polluted ponds: The complex impacts of human-altered environments. 67. 
423 Ceballos, G., P. R. Ehrlich, A. D. Barnosky, A. García, R. M. Pringle, and T. M. Palmer. 2015. Accelerated modern human-induced species losses: Entering the sixth mass extinction. Science Advances 1:e1400253.

426 Central Intelligence Agency. 2013. The World Factbook 2012-13. Central Intelligence Agency.

427 Christensen, R. H. B. 2019. Regression Models for Ordinal Data [R package ordinal version 2019.12-10].

428 Corsi, S., D. Graczyk, S. Geis, N. Booth, and K. Richards. 2010. A fresh look at road salt: aquatic toxicity and water-quality impacts on local, regional, and national scales. Environmental Science \& Technology 44:7376-7382.

Costanzo, J. P., and R. E. Lee. 2005. Cryoprotection by urea in a terrestrially hibernating frog. Journal of Experimental Biology 208:4079-4089.

Costanzo, J. P., and R. E. Lee. 2013. Avoidance and tolerance of freezing in ectothermic vertebrates. Journal of Experimental Biology 216:1961-1967.

Costanzo, J. P., A. M. Reynolds, M. C. F. do Amaral, A. J. Rosendale, and R. E. Lee Jr. 2015. Cryoprotectants and extreme freeze tolerance in a subarctic population of the wood frog. PLoS ONE 10:e0117234.

Cunningham, A., T. S. Langton, P. Bennett, J. Lewin, S. Drury, R. Gough, and S. Macgregor. 1996. 
445

446

447

448

449

450

451

452

453

454

455

456

457

458

459

460

461

462

463

464

465

466

Denoël, M., M. Bichot, G. F. Ficetola, J. Delcourt, M. Ylieff, P. Kestemont, and P. Poncin. 2010.

Cumulative effects of road de-icing salt on amphibian behavior. Aquatic Toxicology 99:275-280.

Docherty, D. E., C. U. Meteyer, J. Wang, J. Mao, S. T. Case, and V. G. Chinchar. 2003. Diagnostic and molecular evaluation of three iridovirus-associated salamander mortality events. Journal of Wildlife Diseases 39:556-566.

Dugan, H. A., S. L. Bartlett, S. M. Burke, J. P. Doubek, F. E. Krivak-Tetley, N. K. Skaff, J. C. Summers, K. J. Farrell, I. M. McCullough, A. M. Morales-Williams, D. C. Roberts, Z. Ouyang, F. Scordo, P. C. Hanson, and K. C. Weathers. 2017. Salting our freshwater lakes. Proceedings of the National Academy of Sciences:201620211.

Dulac, J. 2013. Global land transport infrastructure requirements. Paris: International Energy Agency 20:2014.

Emer, C., M. Galetti, M. A. Pizo, P. Jordano, and M. Verdú. 2019. Defaunation precipitates the extinction of evolutionarily distinct interactions in the Anthropocene. Science Advances 5:eaav6699.

Fahrig, L., and T. Rytwinski. 2009. Effects of roads on animal abundance: an empirical review and synthesis. Ecology and Society 14.

Forman, R. T. T., and R. D. Deblinger. 2000. The ecological road-effect zone of a Massachusetts (USA) suburban highway. Conservation Biology 14.

Forzán, M. J., R. V. Vanderstichel, C. T. Ogbuah, J. R. Barta, and T. G. Smith. 2012. Blood collection from the facial (maxillary)/musculo-cutaneous vein in true frogs (family Ranidae). J Wildl Dis 48:176-180.

Glista, D. J., T. L. DeVault, and J. A. DeWoody. 2008. Vertebrate road mortality predominantly impacts amphibians. Herpetological conservation and Biology 3:77-87. 
467 Gordon, M. S., and V. A. Tucker. 1965. Osmotic regulation in the tadpoles of the crab-eating frog (Rana cancrivora). Journal of Experimental Biology 42:437-445.

Grant, E. H. C., D. A. Miller, and E. Muths. 2020. A Synthesis of Evidence of Drivers of Amphibian Declines. Herpetologica.

Green, D. M., M. J. Lannoo, D. Lesbarrères, and E. Muths. 2020. Amphibian population declines: 30 years of progress in confronting a complex problem. Herpetologica 76:97-100.

473 Green, D. M., L. A. Weir, G. S. Casper, and M. J. Lannoo. 2014. North American amphibians: distribution and diversity. Univ of California Press.

Greenwald, L. 1972. Sodium Balance in Amphibians from Different Habitats. Physiological Zoology 45:229-237.

Hadfield, C. A., and B. R. Whitaker. 2005. Amphibian emergency medicine and care. Pages 79-89 in Seminars in Avian and Exotic Pet Medicine. Elsevier.

Hall, E. M., S. P. Brady, N. M. Mattheus, R. L. Earley, M. Diamond, and E. J. Crespi. 2017. Physiological consequences of exposure to salinized roadside ponds on wood frog larvae and adults. Biological

Hall, E. M., J. L. Brunner, B. Hutzenbiler, and E. J. Crespi. 2020. Salinity stress increases the severity of Conservation 209:98-106.

Huber, M., A. Welker, and B. Helmreich. 2016. Critical review of heavy metal pollution of traffic area runoff: Occurrence, influencing factors, and partitioning. Science of the Total Environment 541:895-919. frog, Acris crepitans. Canadian Journal of Zoology 77:1240-1246. 
490

491

492

493

494

495

496

497

498

499

500

501

502

503

504

505

506

507

508

509

510

511

512

Karraker, N. E., J. P. Gibbs, and J. R. Vonesh. 2008. Impacts of road deicing salt on the demography of vernal pool-breeding amphibians. Ecological Applications 18:724-734.

Karraker, N. E., and G. R. Ruthig. 2009. Effect of road deicing salt on the susceptibility of amphibian embryos to infection by water molds. Environmental Research 109.

Kaushal, S. S., P. M. Groffman, G. E. Likens, K. T. Belt, W. P. Stack, V. R. Kelly, L. E. Band, and G. T. Fisher. 2005. Increased salinization of fresh water in the northeastern United States. Proceedings of the National Academy of Sciences of the United States of America 102:13517-13520.

Kaushal, S. S., G. E. Likens, M. L. Pace, R. M. Utz, S. Haq, J. Gorman, and M. Grese. 2018. Freshwater salinization syndrome on a continental scale. Proceedings of the National Academy of Sciences 115:E574-E583.

Kling, K., J. Costanzo, and R. Lee. 1994. Post-freeze recovery of peripheral nerve function in the freezetolerant wood frog, Rana sylvatica. Journal of Comparative Physiology B 164:316-320.

Kuznetsova, A., P. B. Brockhoff, and R. H. Christensen. 2017. ImerTest package: tests in linear mixed effects models. Journal of statistical software 82:1-26.

Lalo, J. 1987. The problem of road kill. American forests (USA).

Layne Jr, J. R., and R. E. Lee Jr. 1987. Freeze tolerance and the dynamics of ice formation in wood frogs (Rana sylvatica) from southern Ohio. Canadian Journal of Zoology 65:2062-2065.

Lee, R. E., J. P. Costanzo, E. C. Davidson, and J. R. Layne Jr. 1992. Dynamics of body water during freezing and thawing in a freeze-tolerant frog (Rana sylvatica). Journal of Thermal Biology 17:263-266.

Leigh, D. M., A. P. Hendry, E. Vázquez-Domínguez, and V. L. Friesen. 2019. Estimated six per cent loss of genetic variation in wild populations since the industrial revolution. Evolutionary Applications 12:1505-1512. 
513 Lenth, R., H. Singmann, J. Love, P. Buerkner, and M. Herve. 2018. Emmeans: Estimated marginal means, aka least-squares means. $R$ package version 1:3.

515 Marsalek, J., Q. Rochfort, B. Brownlee, T. Mayer, and M. Servos. 1999. An exploratory study of urban runoff toxicity. Water science and technology 39:33-39.

517 Martof, B. S., and R. L. Humphries. 1959. Geographic Variation in the Wood Frog Rana sylvatica. American Midland Naturalist 61:350-389.

McIntyre, J. K., J. I. Lundin, J. R. Cameron, M. I. Chow, J. W. Davis, J. P. Incardona, and N. L. Scholz. 2018. Interspecies variation in the susceptibility of adult Pacific salmon to toxic urban stormwater runoff. Environmental Pollution 238:196-203.

522 Miller, D., M. Gray, and A. Storfer. 2011. Ecopathology of ranaviruses infecting amphibians. Viruses 3:2351-2373.

Mortensen, D. A., E. S. Rauschert, A. N. Nord, and B. P. Jones. 2009. Forest roads facilitate the spread of invasive plants. Invasive Plant Science and Management 2:191-199.

526 Mullaney, J. R., D. L. Lorenz, and A. D. Arntson. 2009. Chloride in groundwater and surface water in areas underlain by the glacial aquifer system, northern United States. U.S. Geological Survey Scientific Investigations Report 2009-5086.

529 O'Connor, J. H., and T. A. Rittenhouse. 2016. Snow cover and late fall movement influence wood frog survival during an unusually cold winter. Oecologia 181:635-644.

531 Park, J. K., and Y. Do. 2020. Physiological response of Pelophylax nigromaculatus adults to salinity exposure. Animals (Basel) 10: 1698.

533 Pessier, A. P. 2009. Edematous frogs, urinary tract disease, and disorders of fluid balance in amphibians. Journal of Exotic Pet Medicine 18:4-13. 
Reed, R. A., J. Johnson-Barnard, and W. L. Baker. 1996. Contribution of roads to forest fragmentation in the Rocky Mountains. Conservation Biology 10:1098-1106.

Riley, S. P., J. P. Pollinger, R. M. Sauvajot, E. C. York, C. Bromley, T. K. Fuller, and R. K. Wayne. 2006. FAST-TRACK: A southern California freeway is a physical and social barrier to gene flow in carnivores. Molecular Ecology 15:1733-1741.

Rosenberg, K. V., A. M. Dokter, P. J. Blancher, J. R. Sauer, A. C. Smith, P. A. Smith, J. C. Stanton, A.

Sanzo, D., and S. J. Hecnar. 2006. Effects of road de-icing salt ( $\mathrm{NaCl})$ on larval wood frogs (Rana Science 366:120.

Shepard, D. B., A. R. Kuhns, M. J. Dreslik, and C. A. Phillips. 2008. Roads as barriers to animal movement in fragmented landscapes. Animal Conservation 11:288-296.

547 Stockwell, M., J. Clulow, and M. Mahony. 2015. Evidence of a salt refuge: chytrid infection loads are suppressed in hosts exposed to salt. Oecologia 177:901-910.

Storey, K. B., and J. M. Storey. 1988. Freeze tolerance in animals. Physiological Reviews 68:27-84.

Symstad, A. J., D. Tilman, J. Willson, and J. M. Knops. 1998. Species loss and ecosystem functioning: effects of species identity and community composition. Oikos:389-397. characterization of urban stormwater with bioanalytical tools. Water Research 47:5594-5606.

Trombulak, S. C., and C. A. Frissell. 2000. Review of ecological effects of roads on terrestrial and aquatic communities. Conservation Biology 14:18-30. Rana cancrivora. Zoological Science 7:p73-78. 
bioRxiv preprint doi: https://doi.org/10.1101/2021.03.23.436008; this version posted March 23, 2021. The copyright holder for this preprint (which was not certified by peer review) is the author/funder, who has granted bioRxiv a license to display the preprint in perpetuity. It is made available under aCC-BY 4.0 International license.

558 Urban, M. C. 2006. Road facilitation of trematode infections in snails of northern Alaska. Conservation

559

Biology 20:1143-1149.

560

561 


\section{Figures}

563 Figure 1. Study sites, edema prevalence, and jump performance. Panel A: Edema was scored in frogs from 38 ponds located within three regions in New England, from south to north: Southern Connecticut, Northeastern Conecticut, and the Upper Valley in Vermont/New Hampshire. Locations of roadside ponds (filled circles) and woodland ponds (open circles) are shown; points were jittered to reduce overlap. Panel B: Edema increased with increasing conductivity (a proxy for road salt). Diamonds ( $\pm 1 \mathrm{SE}$ ) represent pond-level average edema. Circles show individual data points, jittered to reduce overlap. Regression line was estimated with a linear model of pond-level averages for both edema and conductivity. Panel C: Edema was more severe in roadside ponds. Each point represents edema for a unique frog. Points are jiggered vertically and horizontally to reduce overlap. Violin plots show density distribution. Means $( \pm 95 \% \mathrm{Cl})$ for each population type are indicated by open diamonds. Panel D: Edema compromised jumping performance for (right) more northerly $(P=0.016)$ but not (left) more southerly 575

A

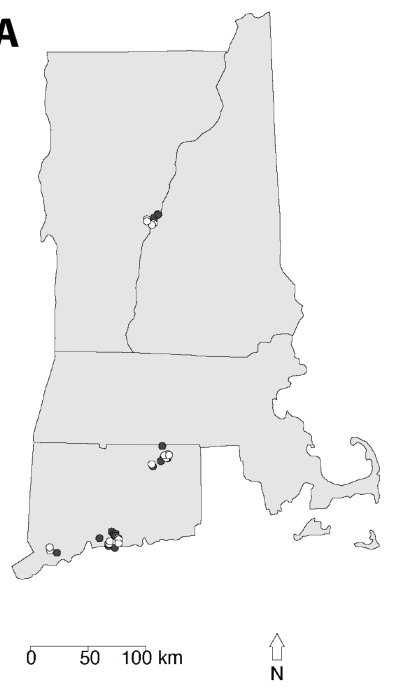

C

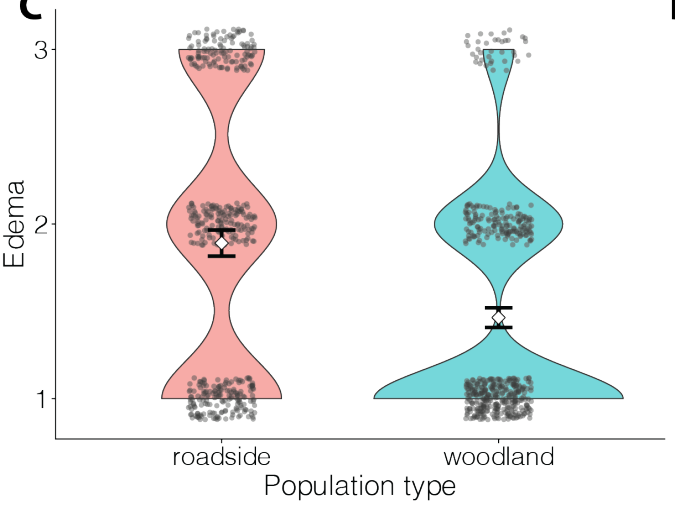

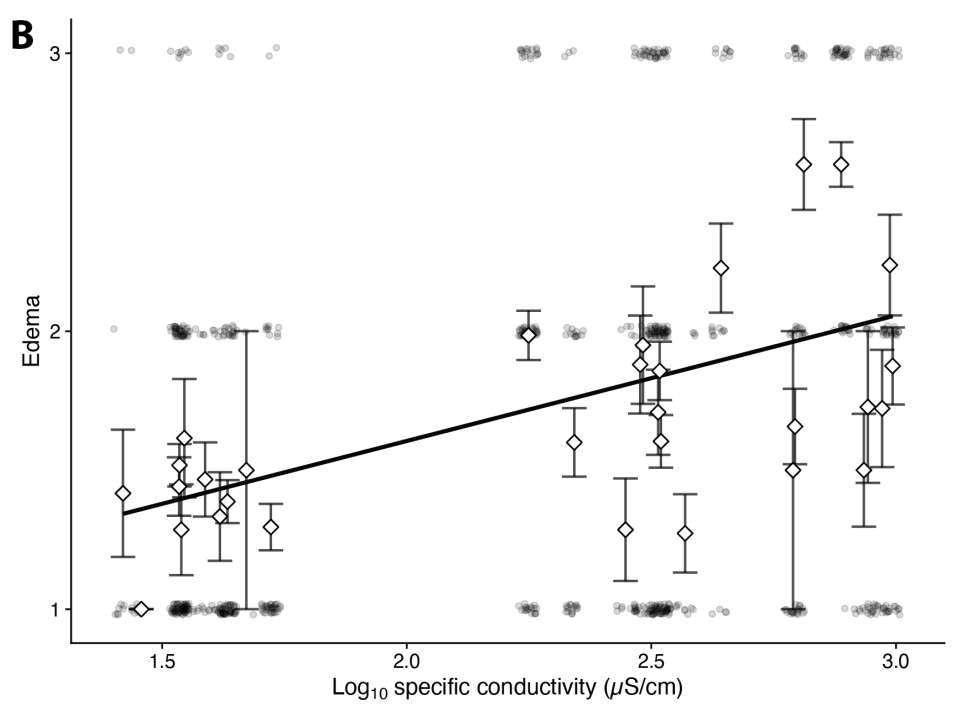

D

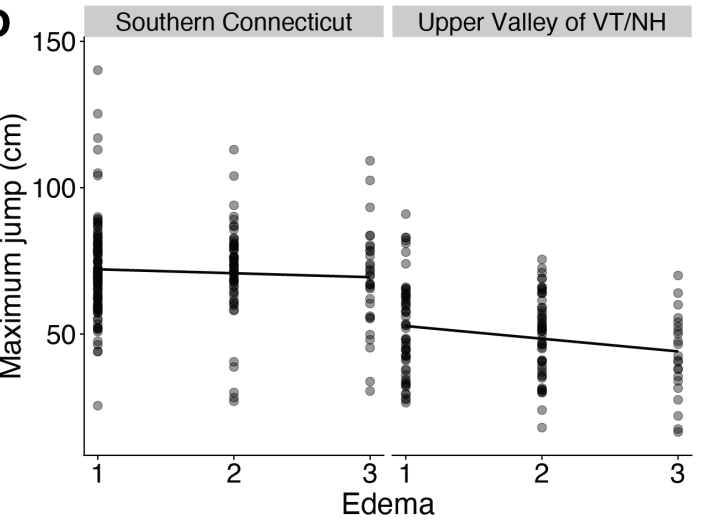


bioRxiv preprint doi: https://doi.org/10.1101/2021.03.23.436008; this version posted March 23, 2021. The copyright holder for this preprint (which was not certified by peer review) is the author/funder, who has granted bioRxiv a license to display the preprint in perpetuity. It is made available under aCC-BY 4.0 International license.

577

Figure 2. Edema and water balance. (A) On gross dissection of the edematous frog (top), edema fluid rapidly dissipated from the subcutis (not visible), and was evident to a much lesser degree in the coelomic cavity. Testes were well developed. Marked subcutaneous edema is evident in an edematous frog (bottom left) compared to a non-edematous frog (bottom right). Bars $=1 \mathrm{~cm}$. (B) On histology, the grossly edematous animal exhibited subcutaneous edema (asterisk, top left) not evident in the non-edematous animal (asterisk, top right). Marked serous atrophy of fat was evident in bone marrow of the edematous animal (asterisk, bottom left) in comparison to non-edematous animals with greater retention of intact adipocytes within bone marrow (asterisk, bottom right). Bars $=50 \mu \mathrm{m}$, hematoxylin and eosin. (C) Change in adult male mass relative to body size (i.e. body condition index, or ' $\mathrm{BCl}$ ') during a controlled breeding experiment is shown for different exposure waters. Mass was measured before and after breeding. Delta $\mathrm{BCl}$ of 1 (dashed line) indicates no change. Experimental exposure to (far left) roadside pond water caused frogs from roadside ponds gain or maintain water on average during the breeding period. In contrast, on average, frogs from woodland ponds exposed to (left center) woodland water lost mass. Similarly, individuals exposed to spring water - whether from (right center) roadside ponds or (far right) woodland ponds - lost mass on average. Raw data are shown as gray circles. Violin plots and boxplots are overlain. White diamonds and error bars represent estimated marginal means and corresponding $95 \%$ confidence intervals.
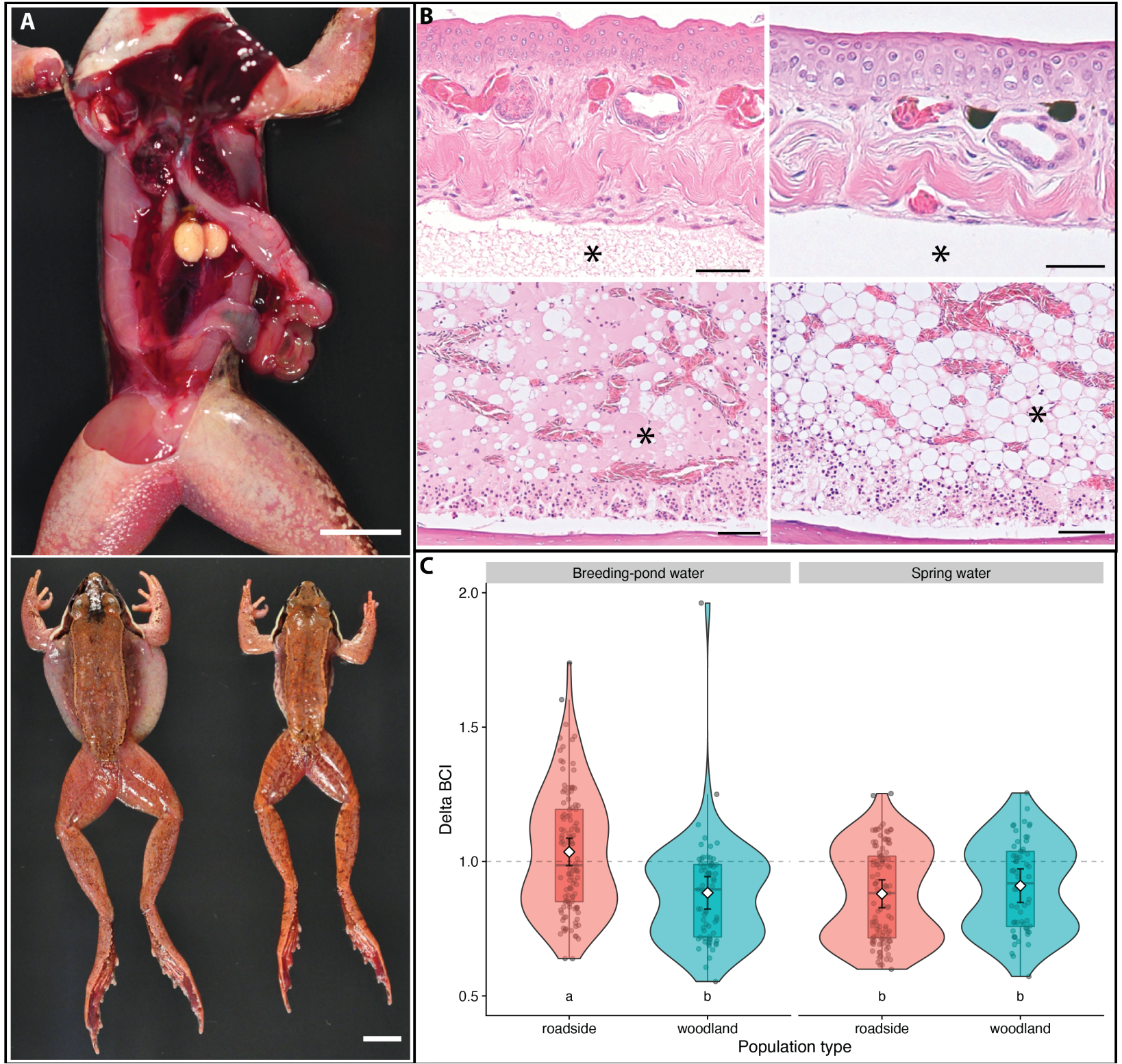